\title{
Antibiotic overprescribing a growing problem
}

\author{
Cite as: CMAJ 2017 February 6;189:E222. doi: 10.1503/cmaj.1095383
}

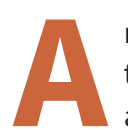
multi-site, multi-study investigation of prescribing patterns among American physicians is revealing widescale overuse and misuse of antibiotics.

The revelations carry "powerful" implications for Canadian physicians as well, says Edmonton-based Dr. Lynora Saxinger, past-chair of the Antimicrobial Stewardship and Resistance Committee of the Association of Medical Microbiology Infectious Disease Canada. "Our overall prescribing pattern in Canada is fairly similar."

Initial study findings, published in May 2016 in the Journal of the American Medical Association (JAMA), showed upwards of $30 \%$ of prescriptions written by US doctors for all indications during 2010-2011 may have been inappropriate. For example, half of prescriptions for acute respiratory conditions - 110 million - may not have been needed.

The study was conducted by the Outpatient Antibiotic Use Target-Setting
Workgroup, comprised of 20 investigators in almost as many US states, and was spearheaded by the US Centers for Disease Control and Pew Charitable Trusts.

A follow-on study from the workgroup, published in JAMA Internal Medicine in December 2016, concluded that in 20102011 physicians correctly prescribed recommended first-line antibiotics only half of the time during patient visits for otitis media, sinusitis and pharyngitis - some 40 million incorrect prescriptions in all.

Both studies rely on data from 184032 ambulatory care visits from the National Ambulatory Medical Care Survey, which samples office-based physicians, and the National Hospital Ambulatory Medical Care Survey, which samples hospital outpatient and emergency departments.

"We knew that misuse was occurring based on local studies," says Dr. David Hyun, a coauthor of both studies. "But at the national level what surprised us was the vast scale of unnecessary prescrip-

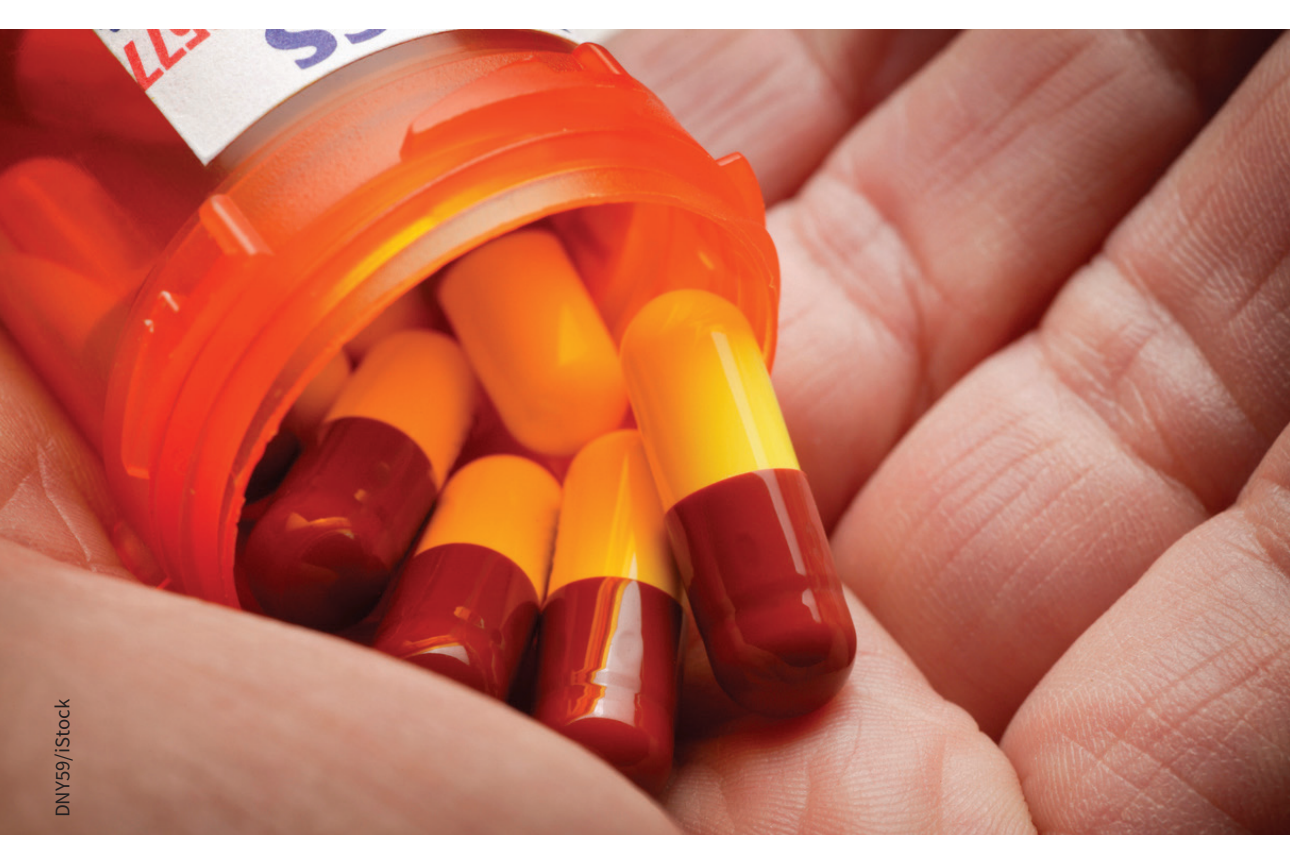

Upwards of $30 \%$ of antibiotic prescriptions written by US doctors for all indications during 2010-11 may have been inappropriate. tions, and inappropriate prescription."

These two studies have created "an initial baseline" for further investigations, says Hyun. The workgroup is now combing through data from walk-in community clinics, and long-term care and urgentcare facilities.

The workgroup's goal is to quantify antibiotic misuse to inform the 2015 US National Action Plan for Combating Antibiotic-Resistant Bacteria. That five-year, \$1.2-billion plan aims to reduce inappropriate outpatient antibiotic use by $50 \%$ by 2020 .

Based on what the workgroup has now revealed, says Hyun, a $15 \%$ reduction in overall antibiotic use would be necessary to reduce misuse by $50 \%$.

Saxinger says Canada should be emulating this research. "I'm not aware anyone is doing anything like this here in Canada," she says.

At the Public Health Agency of Canada in Winnipeg, Dr. Michael Mulvey, chief of Antimicrobial Resistance and Nosocomial Infections at the National Microbiology Laboratory, says that although hospital levels of antimicrobial resistance are being tracked, national antibiotic resistance surveillance does not include Canadian communities. He warns that this gap is worrisome.

His concern echoes the warning in a 2014 report coauthored by Saxinger and others. The need for Canadian surveillance is "at a critical point, as antimicrobial resistance [AMR] is becoming a preeminent worldwide threat to the public health," the report states.

"Current systems do not track evolving AMR in the community or hospital and thus cannot support development of meaningful responses through better stewardship of antimicrobial use in community or hospital settings, or in veterinary and in food animal production."

Paul Webster, Toronto, Ontario 